\title{
Oral radiology goes to the next stage
}

\author{
Junichi Asaumi ${ }^{1}$
}

Received: 30 October 2020 / Accepted: 30 October 2020 / Published online: 16 November 2020

(c) Japanese Society for Oral and Maxillofacial Radiology and Springer Nature Singapore Pte Ltd. 2020

Oral Radiology (ORRA) started by publishing two issues a year in 1985. ORRA has published three issues a year from Volume 30, 2014 to Volume 36, 2019. It was increased to four issues a year from Volume 37, 2020.

In November 2018, ORRA was adopted by Medline, which marked a turning point. The number of submissions in ORRA has been increasing ever since. This year, we have already had over 450 submissions by the end of October.

Now we have six Associate Editors and they have handled around ten articles every month. I would like to take this opportunity to express my appreciation to our Associate Editors and reviewers for their hard work. We need more Associate Editors and reviewers because of the increase in submissions to ORRA. Three new Associate Editors will join ORRA from January, 2021. I have asked Dr. Xie-Qi Shi from North Europe, and Dr. Emiko Saito Arita and Dr. Deborah Queiroz Freitas from South America, as Associate
Editors of ORRA. They will help us through active involvement in peer reviews for ORRA.

Our next planned milestone for ORRA is publishing six issues a year (bi-monthly publication), and making it a Q1 journal.

I would like to ask our readers for their cooperation and help in manuscript submissions, reviews and so on.

Thank you again.

Junichi Asaumi,

Editor-in-Chief, Oral Radiology

Springer

Publisher's Note Springer Nature remains neutral with regard to jurisdictional claims in published maps and institutional affiliations.
Junichi Asaumi

asaumi@md.okayama-u.ac.jp

1 Okayama University Graduate School of Medicine, Dentistry and Pharmaceutical Sciences, Okayama, Japan 